\title{
Dez anos do jornal-laboratório OutrOlhar: a história de um projeto de extensão que dá certo
}

Bianca Damas Pereira ${ }^{1}$, Rafael Barbosa Fialho Martins ${ }^{2}$, Joaquim

Sucena Lannes ${ }^{3}$

RESUMO: $O$ artigo faz um levantamento histórico do jornal-laboratório OutrOlhar, produzido pelos estudantes de Jornalismo da Universidade Federal de Viçosa, e identifica de que maneira o veículo vem promovendo a extensão universitária em seus dez anos de existência. $O$ trabalho ainda disserta sobre o projeto de extensão vinculado ao jornal, que amplia o uso do veículo como instrumento pedagógico e aproxima ainda mais o OutrOlhar e seu público leitor.

Palavras chave: Educomunicação, extensão universitária, jornal-laboratório.

Áreas temáticas: Comunicação e educação. 


\section{Ten years of the newspaper-lab OutrOlhar: the history of a successful extension project}

ABSTRACT: This article is a historical survey of the newspaper-lab OutrOlhar produced by journalism students at the Federal University of Viçosa and identifies how come this means of communication has been promoting the university extension in its ten years of existence. This work still lectures on the extension project linked to the paper, which extends the vehicle's use as a pedagogical tool and approaches further OutrOlhar and readers.

Keywords: Educommunication, newspaper-lab, university extension.

Thematic areas: Communication and education.

\section{Diez años del journal-laboratorio OutrOlhar: a história de uno proyecto de extensión que dá certo}

RESUMEN: El presente artículo es un estudio histórico de OutrOlhar, periódico-lab producido por estudiantes de periodismo de la Universidad Federal de Viçosa, e identifica como el vehículo ha estado promoviendo la extensión universitaria en sus diez años de existencia. El trabajo presenta el proyecto de extensión relacionado com el periódico e utilizacion de el vehículo extiende pedagogico e cerca su leitor.

Palabras clave: Educomunicación, extensión Universitaria, Journal-laboratorio.

Áreas temáticas: Comunicación y educación. 


\section{INTRODUÇÃO}

Entre as práticas laboratoriais realizadas no Curso de Comunicação Social/Jornalismo da Universidade Federal de Viçosa (UFV) encontra-se a produção do jornal-laboratório impresso OutrOlhar. O jornal é desenvolvido na universidade como atividade obrigatória, que proporciona aproximação entre o estudante de Jornalismo e a simulação da realidade profissional. A proposta do veículo é produzir conteúdo de qualidade para ser utilizado em salas de aula das escolas do Ensino Médio da cidade, levando-se em conta as potencialidades que o uso de jornais em ambiente escolar pode proporcionar - leitura crítica dos meios de comunicação, interpretação de textos, enriquecimento de vocabulário, entre outras. Este artigo faz uma retrospectiva da história do OutrOlhar, que completa dez anos de atividades em 2013, explorando e discutindo os fatos mais representativos dessa trajetória. O presente trabalho também relata brevemente outro projeto de extensão ligado ao veículo, que contribui para potencialização dos usos do jornal em questão.

\section{Breve história do jornal-laboratório OutrOlhar}

O Curso de Comunicação Social/Jornalismo da Universidade Federal de Viçosa (UFV) implantou a atividade do jornal-laboratório OutrOlhar em 2003, dois anos após a criação do Curso. O jornal faz parte das normas estabelecidas pelo Conselho Nacional de Educação, que visa promover a prática laboratorial entre os estudantes de Jornalismo. Dirceu Fernandes Lopes (1989) destaca a importância do jornal-laboratório, que

é um veículo que deve ser feito a partir de um conjunto de técnicas específicas para um público também específico, com base em pesquisas sistemáticas em todos os âmbitos, o que inclui a experimentação constante de novas formas de linguagem, conteúdo e apresentação gráfica. Eventualmente, seu público pode ser interno, desde que não tenha caráter institucional (LOPES, 1989, p.50).

No contexto da UFV, após vários debates, ficou decidido que o jornal do curso seria destinado à comunidade viçosense como um todo, e "[...] a ideia era que 'o jornal-laboratório fizesse uma integração, que permitisse um olhar diferenciado. Que a cidade conhecesse alguma coisa diferente de dentro da universidade e que a universidade percebesse a cidade de maneira diferenciada"' (DIAS, 2011, p.29).

Desse modo, desde o início até os dias atuais, o OutrOlhar é, em sua essência, uma iniciativa promotora da extensão universitária, 
como destaca o jornalista Élson Rezende de Mello, um dos responsáveis pela criação do veículo-laboratorial: "A gente sugeriu de não fazer um jornal só voltado para a universidade, os estudantes falando sobre problemas de universidade; a gente não queria só isso. Queríamos fazer voltado pra cidade e para algum bairro" (DIAS, 2011, p.29).

Contudo, assim como na maioria dos cursos do Brasil, na UFV o jornal enfrentou diversas dificuldades (limitações financeiras, técnicas), e dependera do esforço dos professores e da adesão de poucos alunos para ser produzido, já que não era atividade obrigatória - apesar de importante.

A partir de agora, pode-se ter um levantamento de todas as edições publicadas de OutrOlhar. Com essa análise, busca-se entender como o jornal cumpriu seu papel enquanto atividade de extensão. Ao todo foram publicadas 36 edições do jornal, que serão abordadas na pesquisa em três categorias:

a) Edições regulares - compreendem 29 edições regulares do jornal, sem caráter extraordinário;

b) Edições especiais - compreendem cinco edições; duas voltadas à fotografia, duas direcionadas a eventos (vestibular) e uma edição extra;

c) Edições esportivas - abarcam duas edições com temática exclusivamente esportiva, produzidas em outra disciplina (COM350 Jornalismo Esportivo).

\section{EDIÇÕES REGULARES}

A primeira edição do OutrOlhar é de novembro de 2003, e contou com a produção de alunos dos anos de 2001 e 2002. A orientação foi dos professores Adriana Araújo Passos, Débora de Carvalho Pereira e Élson Rezende de Mello. A primeira edição teve dois mil jornais impressos, com 12 páginas - número que iria variar até a edição mais recente. O editorial brinca com o fato de o projeto do jornal se iniciar no fim do ano, justificando:

A decisão de publicar o nosso primeiro jornal-laboratório em dezembro [sic] deve-se ao desejo de vê-lo consolidado em 2004. É somente colocando a mão na massa e exercitando nosso ofício que podemos analisar criticamente o nosso trabalho, reconhecendo os seus erros e os seus acertos. Iniciar um projeto no final do ano nos dá a chance de começar janeiro com uma ideia praticamente pronta para ser trabalhada nos próximos meses (EDIÇÃO 1, p.2). ${ }^{4}$ 
Como sugere seu nome, o jornal-laboratório apresenta-se com o objetivo de "[...] um Outro Olhar sobre iniciativas de alunos e professores da UFV". A proposta, extensionista por excelência, é "[...] mostrar ações que envolvam Universidade e cidade, mas sem repetir fórmulas e sem assumir o perfil de uma publicação oficial. Nosso espaço é aberto a todos os olhares". A meta de promover uma integração entre a UFV e Viçosa foi cumprida pela linha editorial. Desde o início o OutrOlhar abordou assuntos pertinentes aos viçosenses, com auxílio de entrevistados da universidade, quando necessário; assim, gradativamente, o propósito de extensão do jornal era cumprido. Essa preocupação pode ser percebida no editorial da terceira edição, que defende que

Tanto o ensino quanto a pesquisa devem ter um comprometimento social. É importante que haja, ainda, um maior diálogo entre os diversos centros de ciências. $\mathrm{O}$ conhecimento deve sair dos gabinetes e atingir efetivamente a população, despindo-se do discurso academicista e respeitando-se as diversidades (EDIÇÃO 3, p.2). ${ }^{5}$

Já na quarta edição, uma polêmica: A matéria de capa era uma reportagem sobre a qualidade da merenda que estava sendo servida nas escolas públicas. A denúncia era de que não havia a elaboração de cardápios, com a orientação ou participação de profissionais da nutrição, preparados a partir dos ingredientes disponibilizados pela prefeitura. A estudante-repórter ouviu diretores de algumas escolas da cidade e demais pessoas envolvidas na questão, os quais falaram sobre o subaproveitamento dos alimentos, e a reportagem gerou polêmica:

Como o jornal era distribuído na cidade, a diretora de uma das escolas, a Escola Municipal Edmundo Lins, tomou conhecimento da matéria. Depois da reportagem publicada, a diretora não gostou. A Prefeitura, menos ainda [...]. A escola entrou com um pedido de indenização contra o editor geral do OutrOlhar e também contra a Universidade Federal de Viçosa, pois acreditavam ser mais fácil receber o valor pedido (cerca de duzentos mil reais) da instituição federal, do que do curso de Comunicação Social ou dos professores e alunos. A alegação inicial era de que a matéria denegria a imagem da escola. Posteriormente, o alvo de discussão passou a ser a foto de capa. Além da direção da escola, a família de um dos meninos que aparecia na foto também se envolveu na causa (DIAS, 2011, p.43).

Após algumas audiências e baseado nas justificativas apresentadas pela defesa, o juiz deu ganho de causa à UFV e ao Curso de 
Comunicação Social. O argumento foi o de que a fotografia havia sido tirada com o consentimento da diretora da escola. Dias (2011) destaca o aprendizado que esse acontecimento gerou:

Esse episódio serviu para que alunos e professores discutissem a importância e a necessidade de uma boa apuração, ouvir todos os lados, produzir uma matéria completa, ter cuidado com as fontes e com as informações, principalmente em reportagens de denúncias [...] (DIAS, 2011, p.44).

Depois de quase quatro anos de existência, o OutrOlhar passou por uma série de alterações; em 2007 foi assumido pelo professor Joaquim Sucena Lannes, que promoveu uma ampla reforma no veículo. Dentre as modificações previstas, uma delas seria uma espécie de "espinha dorsal" - a reformulação da linha editorial.

Primeiramente, era necessário redefinir o público-alvo; outrora voltado à cidade de Viçosa em geral, o OutrOlhar, na concepção de Lannes, deveria se destinar a um público específico e carente de conhecimento, e assim estabeleceu-se: o jornal seria feito para alunos de nível médio das escolas públicas da cidade. Lannes (2009) justifica a escolha:

No meu entender, os alunos dessa faixa etária são sempre cheios de dúvidas e geralmente não encontram brechas para dirimir suas questões no núcleo familiar. Além disso, as escolas públicas são carentes dos recursos financeiros que possibilitam materiais para suprir as deficiências de leitura ou informação necessária a esses jovens, que acabaram se transformando em nosso público-alvo (LANNES, 2009, p.247).

Melo (1985) confirma a necessidade de definição do público-alvo. Segundo ele, “o jornalismo só adquire significado enquanto atividade de informação coletiva na medida em que se estrutura a partir de necessidades existentes numa comunidade, numa sociedade, e busca atender a essas aspirações ou tenta influir na sua configuração" (MELO, 1985 apud LOPES, 1989, p.60). Nesse sentido, Lannes, em entrevista à Dias (2011), acrescenta:

Como o jornal é feito com dinheiro público, nada mais apropriado do que ser voltado para utilidade pública. Além disso, os estudantes secundaristas têm pouco hábito de leitura. Quase todos chegam ao ensino médio com dificuldades de interpretação e de formulação de senso crítico a respeito de temas do cotidiano (DIAS, 2011, p.47). 
Vieira Júnior (2002) discorre sobre a importância da definição da linha editorial do jornal-laboratório como elemento constitutivo da formação dos estudantes que o produzem: "A linha editorial é importante para evitar a interferência tanto no processo ensino-aprendizagem quanto na produção e difusão de um jornal-laboratório. Ela define as diretrizes e características do jornal-laboratório" (VIEIRA JÚNIOR, 2002, p.158).

Desse modo, passaram a ser abarcados alunos das escolas estaduais Effie Rolfs; Raul de Leoni; Doutor Raimundo Alves Torres (ESEDRAT); José Lourenço de Freitas; Alice Loureiro; da escola municipal Coronel Antônio da Silva Bernardes (CASB) e o Colégio de Aplicação da UFV (COLUNI). Vale lembrar que o público do jornal extrapola os muros destas escolas - familiares, colegas e várias outras pessoas podem se tornar leitores do OutrOlhar. Além disso, o jornal passou a ter como motes a informação e a formação cidadã dos leitores, podendo ser utilizado em sala de aula como instrumento pedagógico pelos professores de várias disciplinas.

Em razão do novo projeto editorial, foi necessário realizar mudanças na linguagem utilizada - os redatores passaram a ser instruídos a escrever mais livremente, de modo a obter uma maior aproximação com o leitor, desacostumado com leituras densas e analíticas. Os temas também sofreram modificação: tudo é pensado de acordo com os estudantes leitores, que são ouvidos através de uma pesquisa de opinião que ocorre a cada semestre.

A ideia inicial foi promover o estímulo à leitura pela veiculação de temas cuidadosamente escolhidos a partir de pesquisa realizada junto a esse público. Tal cuidado também se estendeu à redação dos textos que, embora ainda não estejam dentro do ideal, procuram utilizar uma linguagem coloquial e usual dessa faixa etária. Tudo isso sem deixar que as matérias caiam nos tons professorais e na retórica monótona que, certamente, levam o desinteresse e o desestímulo à leitura (LANNES, 2009, p.247).

Logo no primeiro número editado por Joaquim Lannes, de janeiro de 2007, ficaram visíveis as mudanças: novo projeto gráfico - capa colorida, mais ilustrações, nova fonte usada nos textos -, impressão em papel offset, e editorias mais delineadas, que seriam consolidadas nos números seguintes ("Esportes", "Lazer" e "Ciência"). Atente-se para a editoria "Cidadania", pela primeira vez no jornal, que atesta a tentativa de fazer de OutrOlhar um instrumento de uso nas escolas, contribuindo para a formação cidadã dos leitores. 
Acredita-se que a proximidade que os meios estabelecem com o público-alvo atraia os indivíduos para a participação e para exercício da cidadania. O jovem/educando, ao ter contato com o jornal OutrOlhar, encontra temas relacionados ao seu cotidiano e passa a se conscientizar e refletir sobre a realidade à sua volta. Quando se veem naquilo que leem, os alunos visualizam a mudança e passam a se interessar e a querer transformar o espaço em que vivem. Assim, uma das propostas do OutrOlhar se baseia em informação e educação para a cidadania, no sentido em que busca tornar as pessoas mais críticas e participantes da sociedade.

A partir de então, começaram a ser tratados assuntos com teor mais "pedagógico", com matérias próximas a temas vistos na escola, mas feitas com linguagem diferenciada, abordagem simples e divertida.

Todas as matérias veiculadas, à primeira vista, poderiam parecer corriqueiras. Mas com os tratamentos e angulações especiais por parte dos nossos alunos, para atender ao máximo os objetivos do Projeto, as matérias ganharam uma roupagem diferenciada, tornando-se de grande importância não só para informar o leitor, mas também para servir de temática de reflexões e discussões do público-alvo, dentro de suas salas de aula [...] (EDIÇÃO 11, p. 2). ${ }^{6}$

A partir da edição 16, a editoria "Entretenimento" foi excluída e o jornal ganhou novo projeto gráfico - nova logomarca, tamanho maior e diagramação diferenciada. O editorial aborda as modificações no OutrOlhar, as quais seguem a tendência do campo do Jornalismo, que deve se adequar constantemente às atualizações dos meios e das práticas de comunicação:

Um mercado editorial em constante mutação. Um veículo cuja "morte" se anuncia a todo o momento. Por isso, nada mais normal do que a tentativa de renovação e adaptação às novas realidades. Este é um desafio constante para quem escreve para jornal impresso. [...] Com os adventos da TV (de agora em diante com pretensões interativas), da internet e, com as tendências convergentes de todas as mídias, nada mais importante do que pesquisar, inovar e interagir para atrair e manter-se no gosto do público (EDIÇÃO 17). ${ }^{7}$

Atestando a experimentação característica do projeto, os responsáveis pelo jornal - alunos 2007-2010 - pareceram ter uma maior preocupação com o design gráfico, agora mais elaborado e atual. Acompanhando o ritmo de mudanças na educação, a edição 20, de 
novembro de 2009, foi a primeira a se adequar às novas regras ortográficas previstas num acordo entre Brasil e outros países de língua portuguesa, como Portugal, Cabo Verde e São Tomé e Príncipe.

No editorial da edição 22, Joaquim Lannes comemora o reconhecimento do OutrOlhar que, como constava em um selo na capa, foi um dos grandes vencedores do Intercom Sudeste 2010, o maior evento de Comunicação do país. O jornal teve premiações nas modalidades jornal-laboratório, jornal impresso (edição especial) e melhor fotografia jornalística.

Outra conquista foi a repercussão obtida com a reportagem especial "Entre os muros da escola", que fez um amplo levantamento sobre as péssimas condições físicas das escolas de Viçosa e cobrou resultados das autoridades. Como resultado, antes mesmo da circulação da edição, a Secretaria Regional de Educação retirou as crianças das salas em condições precárias onde elas estudavam, como no caso da Escola Estadual José Lourenço de Freitas.

A partir de novembro de 2010, celebrando sete anos de história, o OutrOlhar ganhou nova diagramação e formato, que segundo o editorial, "traz mais leveza e identidade" ao jornal, algo pertinente ao público-alvo, alunos das escolas públicas. Outro diferencial foi a publicação de um suplemento especial sobre os vinte anos da criação do Estatuto da Criança e do Adolescente (ECA). Ainda naquele ano, o jornal foi contemplado com o Prêmio Arthur Bernardes, concedido pela UFV, devido ao mérito em extensão do projeto.

Nesse sentido, outra ação do jornal deve ser destacada: a função de divulgador de diversos projetos de extensão da UFV. Em quase todas as edições é possível ver matérias que apresentam atividades de extensão aos estudantes de Ensino Médio, estimulando a participação ativa deles.

Já em 2011, OutrOlhar continuou a se consolidar como um dos melhores veículos laboratoriais do Brasil, título confirmado por mais uma conquista do Prêmio Expocom Sudeste, no qual ficou em primeiro lugar na categoria jornal-laboratório.

Por fim, nas edições de novembro e dezembro de 2011, foram publicados suplementos especiais, um "guia" com as principais profissões que as universidades mineiras oferecem, uma reivindicação antiga dos leitores do OutrOlhar que estão no $3^{\circ}$ ano, prestes a tentar o vestibular. A série "Você de olho no futuro" presta, então, um serviço de utilidade pública ao leitor, praticando o jornalismo do gênero instrucional (MELO, 1992). 


\section{EDIÇÕES ESPECIAIS}

O OutrOlhar também teve algumas edições especiais, confeccionadas em anos diferentes e com finalidades específicas. A primeira dessas edições foi publicada em dezembro de 2009, a pedido da Diretoria de Vestibular e Exames (DVE), para apresentar a UFV aos candidatos do processo seletivo daquele ano, futuros calouros da instituição. Com tiragem recorde - 25 mil exemplares - o jornal contou com dicas de lazer, matéria sobre moradia em Viçosa e a vida na universidade.

Já em abril de 2010, saiu a edição "OutrOlhar de Viçosa”, dedicada exclusivamente à publicação de fotografias produzidas pelos alunos da disciplina Fotografia (COM 261) daquele ano. A edição posterior também foi destinada aos futuros estudantes da UFV, mas agora com foco nos cursos oferecidos pela instituição, com vistas a ajudar os leitores a escolher a profissão. Em 2011, mais uma edição fotográfica foi lançada: desta vez, toda colorida, foi inspirada no projeto gráfico da extinta revista Fatos e Fotos e trouxe fotografias realizadas pelos alunos.

\section{EDIÇÕES ESPORTIVAS}

Em 2011 surgiu outra novidade: OutrOlhar Edição Especial Esportes, projeto especial produzido por alunos da disciplina "Jornalismo Esportivo (COM 350)”. Assim, a iniciativa pioneira no Curso contribuiu para iniciar os estudantes no ramo do jornalismo esportivo e promover, mais uma vez, o enriquecimento da prática laboratorial característica do OutrOlhar.

\section{JORNAL NA SALA DE AULA}

O contato do estudante com a sua realidade, através das notícias do jornal, já é um fator positivo, pois o torna um conhecedor do contexto em que ele vive, algo que dificilmente seria possível no caso de um livro didático, por exemplo. Assim, de conhecedor da realidade o estudante passa a vê-la com um olhar crítico, pois tem relação direta com aquilo que lê. Tal posicionamento crítico é fundamental para a formação integral do aluno, que passa a ver na leitura um meio para participação ativa na comunidade.

Outros fatores atestam a contribuição que o uso de jornais pode proporcionar às aulas: atualidade e diversificação de conteúdos; interdisciplinaridade; linguagem acessível e caráter documental dos fatos registrados (DINIZ, 2004). Assim, além de contribuir para a formação do cidadão leitor, os jornais ainda acenam como instrumentos 
estimuladores e desmistificadores do processo de leitura. Escritos, em sua maioria, em linguagem direta e simples, esses veículos aproximam o hábito de ler aos alunos, que muitas vezes acostumados a textos e narrativas didáticos que nada têm a ver com sua realidade, sentem-se desmotivados a se debruçar sobre tipos de leituras ditas "não escolares". Desse modo, o contato com o texto de periódicos pode interferir no hábito de leitura dos estudantes, que refletem um "padrão brasileiro" identificado por Melo (2006):

Um dos traços marcantes da evolução cultural brasileira é sem dúvida a resistência à leitura. Somos um país onde pouco se lê. De um lado, o problema reflete a marginalização social a que tem sido condenada a maior parte da nossa população, vivendo em condições tão precárias que o consumo de produtos culturais, como os impressos, constitui um luxo desmedido, principalmente para quem precisa lutar todo dia pela comida, pela roupa, pela habitação (MELO, 2006, p.161).

Silva e Viana (1997) destacam o uso do jornal na sala de aula como instrumento de auxílio na elaboração de gêneros textuais exigidos na ementa do Ensino Médio - notícia; reportagem; anúncio; carta; artigo de opinião; resumo etc. Além disso, as matérias jornalísticas podem ser utilizadas em outras áreas do conhecimento, o que endossa a necessidade da incorporação do jornal impresso às atividades educativas, seja no Ensino Básico, Fundamental ou Médio.

Disciplinas como Matemática, Inglês, Educação Artística e Educação Física parecem não encontrar elo entre o seu conteúdo programático e o mundo representado diariamente pelos jornais, mas o que não há mesmo é um despertar para a possibilidade de uso, uma busca de alternativas que facultem o aproveitamento das matérias jornalísticas pelos professores (SILVA \& VIANA, 1997, p.81).

Desse modo, o jornal se mostra adequado para servir às demandas escolares, pois alia conteúdos pertinentes aos leitores e linguagem de assimilação mais fácil, o que reitera a necessidade de ser trabalhado nas aulas. Fotografias, manchetes em letras maiores e texto mais simples, legendas explicativas, tabelas e infográficos são apenas alguns dos atrativos encontrados no jornal, cuja leitura amplia o vocabulário, ajuda na fixação de conhecimento e exercita a compreensão de textos, competências caras ao estudante que almeja sucesso escolar (DINIZ, 2004). Campo (2005) confirma tais ideias, e diz que 
diante do atual sistema de educação brasileiro, o jornal em sala de aula é um elemento de aprendizagem e interdisciplinaridade. Torna as aulas mais dinâmicas e provocadoras. Faz com que os alunos sejam mais participativos, criativos e construtivos em suas representações. Os alunos podem comentar os fatos, opinar, trocar idéias, refletir e participar de discussões (CAMPO, 2005, p.3).

Um exemplo disso é a pesquisa "A circulação dos textos na escola”, realizada por Citelli (2004), que constatou que a adoção de jornais impressos como instrumento didático restringe-se a usos gerais, como colagem de palavras, recorte de figuras para ilustrar trabalhos e demais apropriações meramente automáticas, desprovidas de discussões e até mesmo de exercícios de interpretação. "Quase sempre não se cobra do aluno nem mesmo o entendimento do que supostamente leu, e o trabalho redunda numa apresentação muda de recortes de gravuras e textos" (SILVA \& VIANA, 1997, p.81).

Sem uma proposta de utilização de periódicos, sem material em mãos, sem incentivo da coordenação escolar nem momentos de discussão para se estabelecer um plano de trabalho com o jornal em sala de aula, o professor sente-se inseguro no uso desse material que poderia, na prática, constituir uma fonte revitalizadora do conteúdo curricular (SILVA \& VIANA, 1997, p.89).

Nesse contexto, seria interessante - e necessário - o constante diálogo entre produtores e professores que utilizam o jornal, para que esta utilização ocorra de modo efetivo. Como sugestões, notam-se a elaboração de cartilhas explicativas destinadas aos docentes e encontros esporádicos entre emissores e receptores.

\section{O JORNAL-LABORATÓRIO COMO INSTRUMENTO PEDAGÓGICO}

Empresas jornalísticas em todo o mundo investiram em produtos impressos voltados à utilização em aulas, expressivamente em países como França, Noruega, Dinamarca, Suécia, Estados Unidos, Argentina. No Brasil, o pioneirismo coube ao jornal Zero Hora, de Porto Alegre, que em 1980 iniciou a distribuição nas escolas (DINIZ, 2004).

Segundo dados colhidos no ano de 2002, 40 dos 465 diários brasileiros registrados pela Associação Nacional de Jornais (ANJ) possuíam programas semelhantes, em 15 estados e no Distrito Federal, atendendo a 
aproximadamente 3,5 milhões de estudantes de 8.500 escolas. A iniciativa é interessante tanto para a empresa jornalística quanto para a própria escola, porque de um lado fomenta o gosto pela leitura (estimulando, assim, a formação de futuros assinantes) e ajuda na consolidação de uma boa imagem do jornal, mas também oferece aos professores um recurso de fácil acesso para dinamizar as aulas (DINIZ, 2004, p.8).

Confirmando essa tendência, o OutrOlhar viu no público escolar uma interessante opção de direcionamento de sua produção, seguindo o exemplo de vários jornais comerciais que são distribuídos em escolas. O interesse do jornal-laboratório do Curso de Jornalismo da UFV não é comercial, mas visa os objetivos de fidelização e fomento por hábito de leitura, assim como os jornais comerciais que são aplicados nas escolas.

Como uma maneira de promover a integração entre teoria e prática nos cursos de Jornalismo, o jornal-laboratório oferece diferenciais. Um deles é o fato de o veículo ser gratuito, o que o torna mais acessível; essa é uma peculiaridade que faz toda a diferença se pensarmos no contexto das escolas públicas do Brasil, muitas vezes carentes em relação à disponibilização de meios de comunicação a seus alunos, que ficam limitados ao giz, lousa e livros, apenas.

Campo (2005) relata a experiência do jornal-laboratório Único, da Universidade para o Desenvolvimento do Alto Vale do Itajaí, em Santa Catarina. Hoje o veículo se tornou uma revista laboratorial do curso de Jornalismo, mas durante um período de sua história, ele foi destinado aos alunos da rede pública do Ensino Médio, sendo utilizado frequentemente nas aulas, mostrando ser uma oportunidade - talvez a única - que os alunos têm de estar em contato com jornais impressos. Na época em que o jornal tinha a linha editorial voltada para as escolas, uma

diretora disse [...] que ficou surpresa ao receber cerca de 50 exemplares, pois cada aluno pôde utilizar um jornal, o que normalmente não acontece com os jornais de circulação diária que a escola assina. Geralmente há apenas um exemplar para uma classe inteira (CAMPO, 2005, p.7).

Além disso, o caráter experimental do jornal-laboratório pode ser uma vantagem em relação aos periódicos comerciais, o que abre uma gama de possibilidades de inovações que podem ser exemplo para demais veículos. 


\section{O OUTROLHAR ATUALMENTE: “MODO DE FAZER”}

Embora tenha passado por inúmeras mudanças, o processo de produção e distribuição do OutrOlhar segue uma lógica consolidada pela experiência acumulada em dez anos de atividades. Vale destacar que, devido ao caráter experimental da iniciativa, essa dinâmica pode variar com a substituição dos alunos que produzem o veículo, o que proporciona atualização e dinamismo a ele.

Atualmente, a dinâmica do jornal funciona da seguinte forma: na disciplina Jornal-Laboratório I, logo no início do trabalho com o OutrOlhar, os estudantes do Curso têm aulas a respeito de particularidades do texto jornalístico impresso, conceitos e noções práticas típicas desse tipo de atividade jornalística, como a pauta, modalidades de entrevista, apuração, adequação ao texto de jornal, questões gráficas, diagramação etc. Nessa parte de aulas expositivas, é fornecido o embasamento teórico aos estudantes, algo tão precioso ao trabalho no jornal.

Posteriormente, os alunos realizam uma pesquisa de campo para conhecer e ouvir o público leitor sobre os assuntos de seu gosto, hábitos e temas de interesse. Nesta fase, os alunos fazem um mapeamento em todas as escolas em que o jornal é distribuído, aplicando questionários e realizando entrevistas que permitem compreender melhor o público-alvo - seu contexto social, hábitos de leitura, relação com meios de comunicação e recepção do OutrOlhar. Esta pesquisa é transformada em seminários apresentados para a turma de Jornalismo e permite um contato direto entre os produtores das notícias e seus leitores.

Após a pesquisa, são promovidas reuniões de pauta com toda a turma, que se divide em editorias. Hoje o jornal é dividido nas editorias "Esporte"; "Ciência e Tecnologia"; "Comportamento"; "Vida e Saúde"; "Cidade"; "Meio ambiente"; "Opinião" e "Cultura". Cada aluno elabora uma pauta de acordo com sua editoria, e leva para a sala de aula para discutir o tema com a turma e com o professor. Cabe ressaltar que nem todas as pautas produzidas são publicadas; para a seleção considera-se a qualidade do tema, a qualidade de detalhamento prospectados nas apurações, a qualidade da redação final, a aplicação das regras do Manual de Redação e Estilo do OutrOlhar e a disponibilidade de espaço nas páginas diagramadas.

Depois das Reuniões de Pauta, os alunos partem para a apuração das reportagens e captação das imagens (fotografias) que serão utilizadas na edição, tendo a oportunidade de lidar com as mais variadas fontes. Geralmente, os alunos têm até duas semanas para executar a pauta da edição que está sendo trabalhada; a 
partir disso, a reportagem produzida deve se enquadrar na linha editorial do jornal e no espaço da página (até 30 linhas quando o tema é de grande importância e será manchete de página). Nesse aspecto, os alunos tendem a colocar em prática a sua capacidade de síntese sem perder os detalhes de relevância de cada tema abordado.

Mais precisamente na disciplina Jornal-Laboratório II, os estudantes aprofundam o aprendizado de edição, produzindo a matéria, mas também ficando responsáveis pela reportagem fotográfica, legendas, artes e demais aspectos da edição do jornal. A diagramação fica por conta de cada editoria, que entrega sua parte totalmente diagramada conforme o projeto gráfico, que permanece praticamente o mesmo implantado em novembro de 2010.

Em seguida, o jornal vai para a gráfica da UFV; lá ele é acompanhado por um grupo de alunos (responsáveis pela paginação) em uma atividade denominada "Acompanhamento Gráfico", que visa manter a qualidade gráfica da edição. Após a impressão, o jornal volta para a sala de aula, onde é feita uma avaliação da edição. Posteriormente, as editorias ficam responsáveis por levar os exemplares às escolas de Viçosa, garantindo que o jornal chegue ao público em mãos.

\section{O PROJETO OUTROLHAR}

Em 2007 surgiu o "Projeto OutrOlhar", criado a partir da necessidade de expandir a atuação do jornal e integrá-lo a experiências de pesquisa e extensão para potencializar os usos e reflexões acerca do periódico e da atividade laboratorial impressa.

Assim, um grupo de estudantes de Jornalismo entusiastas do jornal, coordenado pelo editor-responsável, começou a desenvolver pesquisas sobre a análise do jornal e qual seria a melhor forma de atender o público. Com o amadurecimento dos membros do grupo de trabalho e com entrada de novos participantes, os alunos começaram a desenvolver artigos (que foram apresentados em congressos) e um projeto de pesquisa e outro de extensão "anexo" ao OutrOlhar. A seguir, destaca-se este outro projeto de extensão.

\section{EXPERIÊNCIA EXTENSIONISTA}

A partir de 2012, com o crescimento do OutrOlhar, percebeu-se que, por mais que o jornal cumprisse seus objetivos enquanto produto voltado para a comunidade das escolas públicas, ainda era possível 
fazer mais. Assim, surgiu o projeto de extensão "O jornal e as práticas jornalísticas como instrumentos de formação acadêmica e cidadã de estudantes do segundo grau do Ensino Médio de Viçosa" - um novo projeto de extensão derivado do projeto maior, o OutrOlhar.

O Projeto de Extensão conta com o apoio do Programa Institucional de Bolsa de Extensão Universitária (PIBEX-UFV), que oferece uma bolsa a um estudante de graduação para a sua realização, que tenha como objetivo principal compartilhar o conhecimento gerado na universidade com a sociedade. Para a realização das atividades, optou-se pela Escola Estadual Dr. Raimundo Alves Torres (ESEDRAT), que sempre foi receptiva ao jornal OutrOlhar e que por se localizar em um bairro carente de Viçosa, valida ainda mais a importância da extensão no local.

O objetivo do projeto é estimular a leitura e a interpretação, possibilitando um envolvimento maior e mais direto na confecção de um jornal que traz assuntos pertencentes ao cotidiano dos próprios estudantes de Ensino Médio e com vistas à discussão e conscientização cidadã dos alunos.

Dessa forma, acontece a apropriação das edições do jornal $\mathrm{Ou}$ trOlhar e das técnicas jornalísticas como ferramentas pedagógicas e de transformação social, uma vez que em seu conteúdo, o jornal fomenta o debate acerca de temas da sociedade, importantes para a formação crítica dos leitores.

\section{EMBASAMENTO DO PROJETO DE EXTENSÃO}

O Projeto é realizado sob a ótica da educomunicação, entendida como o conjunto de atividades voltadas para o conhecimento do uso dos meios de comunicação numa perspectiva de prática da cidadania. A educomunicação se propõe a planejar e colocar em prática "políticas de comunicação educativa" e pretende criar e desenvolver os "ecossistemas comunicativos mediados pelos processos de comunicação e por suas tecnologias" (SOARES, 2002, p.24). Ela traz uma pedagogia nova que dialoga com as tecnologias tradicionais de ensino.

Uma das questões práticas da educomunicação seria trabalhar com professores e alunos para melhorar os fluxos comunicativos na escola, dentro do ecossistema escolar. É importante entender os ecossistemas educativos como ações mais amplas de comunicação, no que se refere às relações interpessoais entre alunos, professores e funcionários, pensando em espaços abertos de debate, além do acesso democrático às tecnologias de informação. Entende-se por ecossistemas comunicativos, (conceito introduzido por Jésus Martin-Barbero) a "organização do ambiente, a disponibilização dos recursos, o modus faciendi dos su- 
jeitos envolvidos e o conjunto das ações que caracterizam determinado tipo de ação comunicacional" (SOARES, 2000, p.22, grifo do autor).

Após o equilíbrio deste ecossistema, a escola se posiciona com relação à mídia e passa, assim, a apropriar-se dos meios de comunicação de forma avaliativa, crítica e a produzir a própria mídia. Em todas estas atividades, os meios representam uma nova pedagogia e possibilidade de aprendizado. Dentro da educação não formal (estruturada, com conteúdos maleáveis e sem tempos e locais fixos), auxiliam também no hábito de leitura. Entendemos a leitura como uma prática importante para a formação acadêmica, mas também para a formação cívica, crítica e para uma "leitura do mundo" e sabemos da carência desta atividade em nosso país por diversos fatores, como econômicos, sociais e culturais.

\section{METODOLOGIA E ATIVIDADES DESENVOLVIDAS}

$\mathrm{Na}$ versão piloto do projeto, no primeiro momento realizou-se uma entrevista semiestruturada com os estudantes para conhecer os participantes, a relação deles com os meios de comunicação, com o OutrOlhar e hábito de leitura. A partir desses dados, as atividades foram direcionadas e trabalhadas conforme o estabelecido junto à professora de Português da turma, que cedeu algumas aulas para execução do projeto. As atividades ocorreram em três instâncias:

- Crítica à mídia: atividades de leitura e interpretação dos conteúdos veiculados pelo OutrOlhar. Ao selecionar e discutir os textos, os alunos se posicionaram de forma crítica e puderam expor suas opiniões;

- Aprendizado das técnicas e conceitos jornalísticos: foram realizadas oficinas de texto jornalístico, fotografia e diagramação. Ao conhecer o fazer jornalístico, os alunos puderam entender como o conteúdo é elaborado e desenvolveram habilidades para produzir um veículo. A elaboração do texto jornalístico conciso e objetivo aprimorou e contribuiu para aprendizado de redação;

- Elaboração de um jornal mural: após a capacitação, os alunos da ESEDRAT produziram seu próprio jornal, o School Times (nome escolhido por eles), que trouxe temas como uso de drogas na escola; superlotação dos ônibus escolares; educação ambiental, escolha profissional. Assim, tanto os estudantes como demais professores e funcionários acharam interessante se identificar com o jornal mural e viram o ambiente em que trabalham e estudam em um veículo de comunicação próprio.

$\mathrm{Na}$ última etapa foi realizada outra entrevista com os alunos, contendo uma autoavaliação, e com professores e funcionários, para que fossem avaliadas as atividades desenvolvidas. 


\section{RESULTADOS DO PROJETO DE EXTENSÃO}

Com o objetivo de refletir sobre os resultados do projeto e aprimorá-lo, são utilizados entrevistas, diários de campo (anotações do investigador e sistematização para uma posterior análise) e relatos da comunidade escolar e produção dos alunos (textos e fotografias). Por meio dos dados colhidos durante a versão piloto do projeto, realizado durante o ano de 2012, com alunos do $3^{\circ}$ ano da ESEDRAT, foi possível constatar e analisar os impactos da apropriação do jornal e das práticas jornalísticas em sala de aula para o estímulo de leitura e formação cidadã dos estudantes de Ensino Médio.

O Projeto de Extensão mostra que, quando os estudantes se permitem enxergar novas possibilidades e desenvolver um novo olhar para a comunicação, para mídia e para o mundo, este interesse gera resultados. Na elaboração do trabalho em equipe, na construção de métodos, processos e produtos jornalísticos pelos estudantes do Ensino Médio, é possível estabelecer uma maneira crítica de se relacionar com a mídia e a capacidade de entender a sociedade, mediada e influenciada pelos meios de comunicação. Ainda, ao levar os estudantes a praticar o direito à voz e participar mais ativamente de sua comunidade, abre-se a possibilidade para o exercício da cidadania.

Acredita-se que aproximar o jornal OutrOlhar dos estudantes permitiu que eles refletissem sobre a própria leitura e que expandissem este hábito, partindo do conhecimento sobre temas que são de seus interesses, como os trazidos pelo jornal, para aqueles que complementem a mais a informação e formação dos estudantes. Além disso, o próprio fazer jornal com assuntos de seu interesse e entender como ocorrem os processos comunicativos foram motivações que levaram os estudantes a diversificar e aprofundar a leitura.

Além disso, os estudantes de Jornalismo envolvidos no Projeto de Extensão puderam desenvolver habilidades das técnicas jornalísticas ao ter a oportunidade de relacionar a teoria apreendida no Curso durante as oficinas, ao trocar o conhecimento com os estudantes de Ensino Médio.

Atestando os resultados positivos, além do PIBEX que renovou o projeto por mais um ano, a ação, que se desenvolve atualmente com uma turma de $1^{\circ}$ ano na ESEDRAT, recebeu o apoio do Programa "Reinventando o Ensino Médio". A iniciativa é do Governo de Minas Gerais que prevê a disciplina "Comunicação Aplicada" no currículo escolar, com intuito de habilitar os estudantes para mídias variadas e desenvolver a capacidade de comunicação e de interação social. Nessa nova fase, o objetivo principal é produzir um encarte especial feito pelos alunos da escola para ser publicado no Jornal OutrOlhar. 
As atividades também se realizam em uma escola pública da cidade de Paula Cândido, município vizinho de Viçosa.

\section{CONSIDERAÇÕES FINAIS}

Jornais são janelas de papel; através dessas janelas, o aluno pode atravessar as paredes da escola e entrar em contato com o mundo e com a atualidade. Jornais e revistas são, portanto, mediadores entre a escola e o mundo (FARIA apud LANNES, 2009, p.243). A fim de que a mediação entre a escola e o mundo se dê de forma plena, é necessário que os dois pilares do processo estejam preparados para cumprir suas funções.

De um lado, estão os professores, que precisam estar cientes da melhor maneira de se utilizar esse instrumento pedagógico que, apesar de simples, pode trazer muitos resultados. Do outro lado da questão, estão os produtores desses veículos - no caso do OutrOlhar, estudantes de Jornalismo - que devem estar inteirados sobre sua aplicação em aulas para que produzam com qualidade e de acordo com os anseios do público-alvo.

Nas atividades de extensão do OutrOlhar, é nítida a aproximação da universidade com a sociedade como algo importante, pois a iniciativa ajuda a pensar e a testar soluções de problemas através das técnicas profissionais, além de contribuir com diminuição da distância entre a formação profissional e o mercado de trabalho.

Acredita-se que o aprendizado das técnicas jornalísticas e a produção de veículo de comunicação por jovens se tornam uma necessidade e um instrumento pedagógico para que eles desenvolvam as habilidades de escrita e leitura, conheçam melhor o local em que vivem e a eles mesmos, e para promover a cidadania, a autonomia. Também surge a possibilidade de que os estudantes imprimam identidades, posicionando-se de maneira crítica, diferente do que normalmente veem na mídia massiva.

É pensando nos benefícios do jornal em sala de aula para os estudantes de Ensino Médio e na importância do jornal-laboratório para os estudantes de Jornalismo, que o Jornal OutrOlhar se propõe por meio do Projeto OutrOlhar estudar constantemente as melhores formas de atender ao público-alvo, a partir de princípios éticos e cidadãos. Por isso, opta pela dinâmica de estar inserido de modo ativo no dia a dia dos leitores por meio de projetos que possibilitem identificar e analisar os problemas e desafios e atualizar a maneira de fazer jornal, fazer ensino, pesquisa e extensão. 


\section{REFERÊNCIAS BIBLIOGRÁFICAS}

BANDINI, F.P. O olhar dos educomunicadores. Jornal da ANJ 11/2003.

CAMPO, R.L.C. Extensão da universidade às salas de aula do Ensino Médio do Alto Vale. In: $8^{\circ}$ FÓRUM NACIONAL DE PROFESSORES DE JORNALISMO, 2005. Anais... Maceió, Alagoas: Universidade Federal de Alagoas (UFAL). Disponível em http://www.fnpj.org.br/dados/grupos/jornal-laboratorio-do-curso-de-jornalismo-extensao-da-universidade-as-salas-de-aula[14].pdf. Acessado em 23 de abril de 2012.

CITELLI, A.O. Comunicação e educação: a linguagem em movimento. 3.ed. São Paulo: Editora Senac São Paulo, 2004.

DIAS, S.G. OutrOlhar sobre o ensino de jornalismo: uma análise da importância do jornal-laboratório para a formação profissional. Trabalho de Conclusão de curso (graduação). Universidade Federal de Viçosa, Viçosa, 2011.

DINIZ, J.P. O jornal impresso na formação de consciência crítica. Revista da FAEEBA - Educação e Contemporaneidade, Salvador, v.13, n.21, p.129-141, jan./ jun., 2004.

JÚNIOR, A.V. Uma pedagogia para o jornal laboratório. Tese (Doutorado em Ciências da Comunicação) - Departamento de Jornalismo e Editoração da Escola de Comunicações e Artes da Universidade de São Paulo, São Paulo, 2002.

LANNES, J.S. OutrOlhar: uma proposta pedagógica de jornal-laboratório cidadão. Revista de Ciências Humanas, Viçosa, v.9, n.2, jul./dez. 2009. 414p.

LOPES, D.F. Jornal-laboratório: do exercício escolar ao compromisso com o público leitor. São Paulo: Summus, 1989.

MELO, J.M. Gêneros jornalísticos na Folha de S. Paulo. São Paulo: FTD, 1992.

SILVA, Y.J.; VIANA, F.V. O jornal e a prática pedagógica. In: CITELLI, A.O. (org.). Aprender e ensinar com textos não escolares. Vol. 3. São Paulo: Cortez, 1997. p.79-97.

SOARES, I.O. Educomunicação: um campo de mediações. Comunicação \& Educação. São Paulo, set./dez. 2000. p.12-24.

. Gestão comunicativa e educação: caminhos da educomunicação. Rev. Comunicação e Educação, São Paulo, v.8, n.23, p.16-25, jan./abr. 2002. Disponível em: http://www.revistas.univerciencia.org/index.php/comeduc/ article/viewArticle/4172. Acesso em 14 jan. 2012.

\section{NOTAS:}

\footnotetext{
${ }^{4}$ Disponível em http://www.com.ufv.br/producoes/impresso/outrolhar1. Acessado em 04 mai 2013

${ }^{5}$ Disponível em http://www.com.ufv.br/producoes/impresso/outrolhar1. Acessado em 04 mai 2013

${ }^{6}$ Disponível em http://www.com.ufv.br/producoes/impresso/outrolhar11. Acessado em 04 mai 2013

7 Disponível em http://www.com.ufv.br/producoes/impresso/outrolhar17. Acessado em 04 mai 2013
} 